\title{
On some remarkable phenomena in Geissler tubes
}

\section{Prof. E. Reitlinger \& A. Von Urbanitzky}

To cite this article: Prof. E. Reitlinger \& A. Von Urbanitzky (1876) On some remarkable phenomena in Geissler tubes, Philosophical Magazine Series 5, 2:14, 550-552, DOI: 10.1080/14786447608639151

To link to this article: http://dx.doi.org/10.1080/14786447608639151

$$
\text { 曲 Published online: } 13 \text { May } 2009 .
$$

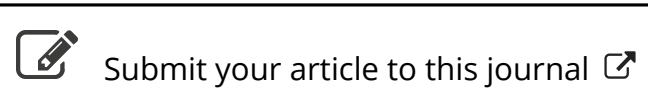

Џ Article views: 2

Q View related articles $\sqsubset$ 
We have operated in the same manner for $B_{1}, C_{1}, D_{1}$, and have drawn up the following Table:-

\begin{tabular}{|c|c|c|c|}
\hline & Coe & re Force. & Magnetic Oapacity. \\
\hline$A_{1}$ & $\ldots \ldots \ldots$ & 47 & 64 \\
\hline$B_{1}$ & $\cdots$ & 45 & 66 \\
\hline $\mathrm{C}_{1}$ & $\ldots \ldots$ & $42 \cdot 5$ & 67 \\
\hline$D_{1}^{2}$ & $\ldots \ldots$ & $33 \cdot 5$ & 68 \\
\hline $\mathrm{E}_{1}^{2}$ & $\ldots \ldots \ldots$ & 13 & 69 \\
\hline
\end{tabular}

The magnetic capacity of soft iron of the same form and weight was 71 .

These approximate relations show how important it was to seek out a method of rigorous measurement of magnetic power.Comptes Rendus de l'Académie des Sciences, Nov. 9, 1876, tome lxxxiii. pp. 857,858 .

ON SOME REMARKABLE PHENOMENA IN GEISSLER TUBES. BY PROF. E. REITLINGER AND A. VON URBANITZKY.

Having, at the commencement of July last, made preparation for continuing our experiments with the aid of a Geissler mercury air-pump, we filled so-called $W$ üllner tubes with different gases, and first investigated afresh the conversion of attraction into repulsion by a higher degree of rarefaction. The experiments were made with air, nitrogen, oxygen, hydrogen, and carbonic acid. They established that, with all these gases, between 4 and 12 millims. pressture the electrical luminous column is attracted, but at about 2-1 millim. it is repelled. Between the two phenomena there is an intermediate stage, in which neither attraction nor repulsion is perceptible. For the first occurrence, however, of perceptible repulsion it was the less possible to find with the different gases one and the same degree of rarefaction, as the repulsion and attraction proved to be dependent on the intensity of the current, and, for example, a luminous column which showed itself indifferent to the finger was caused distinctly to recede from the finger by the insertion of a resistance. Now since the gases in the tube themselves offer different degrees of resistance, we had to take into account at the same time the intensity of the current, in order to render the data comparable. The latter has been found to exert the greatest influence; yet up to the present time we have only numerous results to communicate at the proper time respecting that influence, but have ascertained no general law for it: this we shall endeavour to discover. If rarefaction be continued below 1 millim., in all the cases which we have observed, layers are produced as the rarefaction proceeds, of little breadth and constant in position so far as our observation extends, which either do not retreat before the finger at all, or only when the induction-current is very much wenkened by the insertion of resistances. In consequence of this circumstance the repulsion exhibits a certain maximum during the rarefaction, which again diminishes when the rarefaction is carried still further. A portion of the experiments were made with a somewhat wider tube without any capillary part, which thus was in a certain sense intermediate between the Geissler 
tubes and the so-called electrical egg. Already, when using also the double-barrelled valve air-pump, we had experimented with an electrical egg and atmospheric air and seen a distinct recession of the visible luminous swell in the centre of the egg as the hand was brought nearer from a distance. With five or more centims. distance between the hand and the glass wall of the egg the retreat was very evident; but on the glass being touched, it was changed into an attraction, at least in appearance. When we experimented with the Geissler air-pump and the wide tube above-mentioned, there appeared first, when the induction-current passed through in the usual manner, altogether similar phenomena as in Wüllner's tubes; in particular here also with greater rarefaction the attraction changed into repulsion. But the most striking repulsions were obtained when only one pole of the Ruhmkorfif apparatus was connected with one of the wire electrodes of the tube, and the other was led away to earth. In this case a luminous appearance was perceptible, which, of course, shone brighter only with a higher degree of rarefaction ; but it then exhibited the repulsionphenomenon especially distinct and with a distance of several centims. between the hand and the glass tube. Its appearance was essentially different, according as the positive or the negative pole of the induced open current was connected with the wire; and the strength of the repulsion was also in the latter case much more considerable than in the former. This repulsion increased as the rarefaction was pushed further, and was most intense at the highest degree of rarefaction attained, about 0.2 millim. The singularly favourable result of this experiment induced us to put the wire electrode of the tube into conducting connexion with the conductor of a two-disk Winter electrical machine; and in this case also, with very strong rarefaction, the positive luminous tuft was seen to recede. Experiments for the purpose of testing the principal inferences suggested by the phenomena with the unclosed current are already in preparation. This may also be the place to mention that in none of the cases investigated by us did an ebonite plate when brought near attract or repel.

The striking similarity which is shown between the luminous phenomenon in the unclosed current with great rarefaction and the figures of comets, and the great distance at which in this case the repulsion of the approaching conductor yet acts, reminded us afresh of the question (touched upon in our first communication) whether, in the repulsion under consideration, we have not to do with that very force which makes the tails of comets recede from the sun. That the degrees of rarefaction at which the best results are here obtained lie near 0.2 millim. is only farourable to such an assumption. Further, in those Geissler tubes in the collection of the Second Physical Lehrkanzel in which the recession of the electrified luminous gas-columns before the approaching conductor was first observed, the light which appeared, when examined with the spectroscope, showed distinctly upon a less-bright background those three spectral bands which the spectroscope exhibited also in the flame of illuminating-gas, and which are usually designated 
as a carbon-spectrum, but which, according to Vogel, have likewise formed the spectrum of comets. Moreover, if it be remembered that the repulsion in question, in itself, requires from the repelling body only the conducting quality, and not any free positive or negative electricity, the expectation will not be considered unwarranted that these experiments will be of importance for the electrical theory of the tails of comets and their repulsion-a theory to which several distinguished astronomers have already turned their attention.

In several tubes even at a pressure of 20 millims. (at which the observations commenced) distinct strata appeared; and while the rarefaction was then continued the connexion between the number of the strata and the rarefaction could be proved. It came out that, so long as the chemical quality of the luminous gas-columns and all the other circumstances except the density could be taken as unchanged, the number of the strata diminishes in the ratio of the rarefastion, or, in other terms, that the interval from the centre of one bright stratum to that of the next increases proportionately to the rarefaction. This law may be expected to hold good either strictly or at least very approximately ; for it appeared correct so far as our observation extended. The intensity of the current, too, has a great influence upon the number and clearness of the strata; indeed, by altering it stratified can be changed into unstratified light, and the con verse. By further investigations we shall probably obtain data enabling us here also to state a simple normal relation. The conjecture expressed in our first communication on the phenomena in question, that the magnet increases the number of the strata by condensation, is now verified by the observed increase of the strata proportionate to the density.

It was mentioned in our second communication, that when the tube was filled with oxygen the so-called dark space appeared in grey-green light. This nebulous grey-green light we have obtained, by the employment of the Geissler air-pump after filling with oxygen, in the entire Wülner tube with the sole exception of the capillary part, and found it accompanied by a very vivid brilliance. The observations made on this occasion would agree better with Sarasin's than with Morren's explanation of brightly luminous Geissler tubes. We must reserve the details for a subsequent full communication, as well as those of the experiments of which the chief results have now been described, and also the numerous more or less important collateral phenomena observed, such as-that the grey-green light in oxygen-tubes is neither attracted nor repelled, that on the rarefaction being increased a bright spiral, wound round the positive wire electrode, is developed, that at the tip of this electrode a very bright starlike point makes its appearance on filling the tube with a carbon compound, that the yellow-green light in the glass, which we mentioned in the first communication, constantly accompanies the higher degrees of rarefaction, that in very many cases the so-called dark space is absent, that the current, long continued, has an analyzing effect, \&c.-Kaiserliche Akademie der Wissenschaften in Wien, math.naturw. Classe, Oct. 12, 1876. 